\title{
Multimodal deep learning for multimedia understanding and reasoning
}

Published online: 6 January 2021

(C) Springer Science+Business Media, LLC, part of Springer Nature 2021

Multimedia Tools and Applications gratefully acknowledges the editorial work of the scholars listed below on the special issue entitled "Multimodal Deep Learning for Multimedia Understanding and Reasoning" (SI 1165).

Of 28 papers submitted to this issue, 10 were eventually accepted after a stringent peer review process.

\section{Corresponding Guest Editor}

\section{Yahong Han}

Tianjin University, China

Email: yahong@tju.edu.cn

\section{Guest Editors}

\section{Jingjing Chen}

Fudan University, Shanghai, China

Email: chenjingjing@ fudan.edu.cn

Publisher's note Springer Nature remains neutral with regard to jurisdictional claims in published maps and institutional affiliations. 